\title{
Postgraduate students as plurilingual social actors in UK higher education
}

\begin{abstract}
This paper sets out to develop a finer-grained understanding of the 'plurilingual social actor' within Anglophone higher educational setting. Drawing on data collected as part of The Multilingual University project, I examine how a group of plurilingual postgraduate students taking modules in applied linguistics at a university in London viewed their linguistic repertoires as a resource for the taught curriculum and what their experiences can tell us about the plurilingual social actor. The study opened an institutional space for making linguistic diversity visible and for considering how it was a resource for the curriculum. The findings indicate that multilingual resources play an important role in supporting learning at postgraduate level and reveal ways in which familiarity with English medium education shapes how postgraduate students mobilise their multilingual resources in relation to the taught curriculum. Importantly, the study shows how the plurilingual social actor offers a dynamic, powerful and affirmative identity position that is well aligned with the teaching and learning agenda in higher education. It is my contention that a better understanding of this alignment will allow us to raise awareness of language-as-resource and advance plurilingual pedagogies in the sector.
\end{abstract}

Key words: plurilingual pedagogies, higher education, United Kingdom, postgraduate students, linguistic repertoires, multilingualism

\section{Introduction}

Linguistic diversity is a real asset ... different languages bring in different ideas and worldviews, contributing to the diversity of thoughts at the University.

Being surrounded by linguistic diversity is mentally stimulating. It is also an easy conversation piece, which has allowed me to forge new friendships with people from different cultures.

Linguistic diversity is incredibly rewarding for students - it can allow language learners more exposure to the languages they are studying, it gives language speakers opportunities to express themselves in their native tongue(s), and it allows people from different speech communities to make connections and learn from one another. The 
"everyone speaks English anyway" mentality is limiting the intellectual horizons of learners and native speakers alike.

The statements above are responses from an on-line survey undertaken with postgraduate students taking modules in applied linguistics at Global University, a pseudonym for a university in London. The students were responding to a question on what they would like to tell Global about studying in a linguistically diverse setting as part of a project on The Multilingual University (Preece et al. 2016, 2018). The respondents were not only enthusiastic about linguistic diversity but also had clear ideas about its importance. Despite studying in an English-dominant setting, they did not subscribe to the idea of English only. Moreover, they regarded the assumption that "everyone speaks English" as constraining students' outlooks.

In the decade up to 2018, Global's linguistic ecology, by which I refer to all the languages represented in the institutional population, had become increasingly complex. The number of students had rapidly expanded, doubling in size to just over 42,000, with international recruitment playing a significant role.

Expansion was driven by the internationalisation agenda, which is premised on student and staff mobility and promotes international and intercultural education in a globalised higher education system (see Altbach 2016, Preece 2011). The institution had witnessed a three-fold increase in students recruited from outside the UK, who accounted for 47 per cent of Global's population. 169 countries were represented, with 18,000 of the 20,000 overseas students residing in nations categorised as not 'majority English speaking' by the UK Home Office. The domestic student population had also diversified with the proportion of students classified as Black and Minority Ethnic (BME) rising to 21 per cent of the student body. Institutional data on domicile and ethnicity indicated that most students were likely to come from families where English was in use with other languages or not used at all. Additionally, a significant proportion of the student body had received their schooling through the medium of languages other than English, learning English as part of the 'foreign language' curriculum.

Similarly to other studies (Preece 2009, 2010; Marshall 2010; Martin 2010, Simpson \& Cooke 2010), Global celebrated the cultural diversity of its student body while adopting a less enthusiastic tone about its linguistic diversity. Linguistic diversity was framed in terms of 'language-as-problem' (Hult \& Hornberger 2016; Ruiz 1984) to be addressed through language support programmes designed to remove 'language obstacles'. There were no references to multi- or plurilingualism among the student body in the institutional teaching and learning policy. Consequently, there was no institutional discourse on how to take account of the repertoires of a linguistically and culturally diverse student body in pedagogical practices and curriculum design. 
This paper seeks to problematise myopic views of linguistic diversity in the higher education sector and to contribute to the emerging body of literature on plurilingual pedagogy and language-as-resource-based approaches to teaching and learning in Anglophone higher educational settings (Marshall \& Moore 2013; Preece et al. 2018). It arises from a long-standing commitment to challenge discourses of linguistic deficit in the education system and the idea of 'one language only' and 'one language at a time' (Li \& Wu 2009) in pedagogy and the curriculum. As Li (2018) points out, these discourses continue to prevail in educational institutions. This holds true for the higher education sector in the Anglophone world where English occupies the status of the de facto language for teaching and learning. I aim to develop a finergrained understanding of the 'plurilingual social actor'1 (Coste \& Simon, 2009; Coste et al., 2009) within the sector and show how sanctioning this positioning can encourage students to mobilise multilingual resources for learning the taught curriculum. I argue that the plurilingual social actor is well aligned with the teaching and learning agenda. As such, the plurilingual social actor offers a productive way forward for attending to linguistic diversity in institutional teaching and learning policies and bringing these to bear on pedagogy.

In the next section, I give a brief overview of the plurilingual social actor in the literature before turning to the study on which this paper is based.

\section{Plurilingualism and the plurilingual social actor}

Informing this paper is the Council of Europe's distinction between multi- and pluri- lingualism in the Common European Framework of Reference for Languages (Council of Europe 2001). Both terms refer to situations of language plurality involving two plus languages. While multilingualism refers to the co-existence of languages in a geographical or social space, plurilingualism indicates the diversity of linguistic and cultural resources embodied in the individual (Beacco et al. 2016). As Marshall and Moore (2018) point out, this boundary is not always adhered to and there is often a blurred line between the use of pluri-, multi- and bilingualism. Nonetheless, this differentiation has merit in the way it creates different foci with multilingualism signaling attention to linguistic diversity at institutional or societal level and plurilingualism focused on individuals and how they put their repertoires to use in multilingual settings.

The multi/ pluri distinction enables a view of universities in Anglophone settings as sites of multilingualism by the plurality of languages brought into institutional space by culturally diverse university populations. In the interests

1 The original 'un acteur social' has been translated as 'social actor' and 'social agent' (e.g. Council of Europe 2001; Coste \& Simon 2009). This paper uses 'social actor'. 
of social justice, it also allows us to counter institutional discourses of linguistic deficit by promoting the view of university students as 'plurilingual social actors' with 'linguistic assets' (Coste et al 2009: 19). This allows for a reframing of language support as language development, in which the task for the institution is to figure out ways of harnessing and developing students' repertoires as part of the curriculum.

Key to plurilingualism is the notion of un acteur social, or a socially situated actor (Moore \& Gajo 2009). Marshall and Moore (2013) point out that ideas about the 'plurilingual social actor' have been informed by ongoing debates in sociology on structure and agency. Touraine (2000) is helpful here. In his view, social actors are:

Not defined by their conformity to rules and norms, but by a relationship to themselves, by their capacity to constitute themselves as actors, capable of changing their environment and of reinforcing their autonomy (p. 902).

From this we may surmise that the plurilingual speaker is not a free agent when it comes to communication. The linguistic and cultural norms associated with the context constrain the plurilingual speaker's capacity to exercise autonomy over their linguistic repertoire. As Marshall and Moore (2018) argue, we need to guard against an over-agentive view of plurilingual speakers and attend to ways in which the plurilingual social actor is socially situated. Thus we can see the relationship between multi- and plurilingualism as symbiotic in that what students say and do in relation to their repertoires in Anglophone higher educational settings is shaped by institutional and societal discourses on linguistic diversity and their experiences of institutional practices, particularly those related to pedagogy (Preece 2019).

The plurilingual social actor also embodies a linguistic repertoire, defined as 'all the linguistic and cultural resources available to the speaker' (Beacco et al. 2016: 22). Importantly, this repertoire is viewed holistically rather than as discrete and compartmentalised languages. Lüdi \& Py (2009) put forward the idea of the plurilingual individual as a 'unique speaker-hearer' (p. 154) with 'situated multilingual resources' ( $p .156)$. These resources are drawn from all the languages that an individual has learned, encompassing languages learned naturally as well as those learned formally (Beacco et al. 2016). Crucially, these resources are viewed as having the potential to be mobilised as a way of '[finding] local responses to practical problems' (Lüdi \& Py 2009:158). Two important points are that education institutions are viewed as key sites for the mobilisation of an individual's multilingual resources and that the repertoires of all groups are viewed as valuable regardless of the status that these occupy in wider society.

Importantly, the plurilingual social actor is not located in monolingual native speaker discourses that construct bi- and multilingualism as 'the duplication of competences in two languages (or more)' (Lüdi \& Py 2009: 154). Plurilingual perspectives problematise the idea of bilingualism as the achievement of balance and evenness between two or more languages, coined in phrases such as 'two monolinguals in one body' (Gravelle 1996: 11), arguing that these 
views are inadequate for contemporary societies. Instead, the plurilingual social actor is located in discourses of superdiversity (Vertovec 2007) with embodied multilingual resources that are characterised as uneven and imbalanced. As Coste et al (2009) put it, '[i]mbalance is part of plurilingual competence' (p. 20). This characterisation necessitates a view of the plurilingual social actor as experiencing some linguistic resources as more dominant than others and as subject to change. In sum, the plurilingual social actor experiences linguistic competence as partial and a life-long process that is focused on 'the strategic management of imbalance' (ibid., bold in original). Importantly, this discursive positioning focuses attention on how plurilingual speakers manage multilingual resources and pedagogies that support the management and development of plurilingual competence.

To see how these ideas about the plurilingual social actor can be enacted in higher education, the following sections focus on a study of linguistic diversity at Global University. Given the limited understanding of pluri- and multilingualism across the higher education curriculum (Lazar \& Ryder 2018; Marshall, this Issue; Van Viegen \& Zappa-Hollman, this Issue), emic perspectives are vital for informing and widening the debate about plurilingual pedagogy in the sector.

\section{The Study}

The data for this paper come from a small-scale exploratory study conducted over a 10-month period as part of an institutional initiative to promote researchbased education (see Tong et al. 2018). Informed by The ESRC Multilingual University seminar series ${ }^{2}$ (Preece et al. 2016), the project included MA students as collaborative partners. The study aimed to raise awareness of language as resource and investigate how postgraduate students made use of their linguistic repertoires on campus. 46 postgraduate students taking modules in applied linguistics were recruited. Most were 'internationally mobile' in that they had 'crossed a national or territorial border for the purpose of education and [were] ... enrolled outside their country of origin' (UIS 2015). In all, 15 nationalities were represented, mostly from non English-majority speaking nations. Those from English-dominant countries normally worked overseas in language related professions and were sojourning in the UK for their MA studies. The participants were a linguistically diverse group that reported using 30+ languages. Besides English, these included languages of instruction in schooling in East and South East Asia and Europe, together with languages learned in the course of living and working in a variety of countries. Most participants came from middle-class or more socially elite backgrounds and had access to material wealth to self fund the high costs of studying at

\footnotetext{
2 The Multilingual University seminar series was funded by the Economic and Social Research Council
} 
Global. This was particularly the case for non European Union residents, whose non EU status resulted in higher 'international' tuition fees than domestic/ EU students and the requirement for monthly funds of at least $£ 1265$ to comply with UK visa requirements (Study London ND).

Data collection progressed in 3 phases, summarised in table 1.

Table 1: Phases of data collection

\begin{tabular}{|l|l|l|}
\hline Phase 1 & Phase 2 & Phase 3 \\
\hline $\begin{array}{l}\text { On-line survey } \\
\text { by student project team } \\
\text { members. }\end{array}$ & $\begin{array}{l}\text { Reflective journal over } \\
\text { 3-week period during } \\
\text { teaching }\end{array}$ & $\begin{array}{l}\text { Interviews following end } \\
\text { of academic year } \\
\text { 6 participants from } \\
\text { phase 2 recruited by } \\
\text { team leader. Semi- } \\
\text { structured interviews } \\
\text { phase 1 recruited by } \\
\text { student-team members. } \\
\text { Journal participants } \\
\text { given prompts for } \\
\text { structuring reflections. }\end{array}$ \\
\hline
\end{tabular}

Institutional policies on teaching and learning along with information on language studies were also downloaded from the institutional website. In what follows, I focus primarily on the journal data as these enabled the participants to reflect on the idea of their linguistic repertoires as multilingual resources (Coste \& Simon 2009; Lüdi \& Py 2009) in ways they deemed salient. Drawing on social interactional and performance-based views of narrative (Bamberg 1997, De Fina \& Georgakopoulou 2012), I approached the participants' reflections as a discursive practice for presenting themselves as agentive beings in an Anglophone higher educational setting and negotiating discourses about linguistic diversity. I treated the reflective journals as written interaction in that the journal authors constructed their accounts of their linguistic repertoires and their plurilingual practices with project team members in mind. In the following sections, I turn to the data with the aim of answering the following questions:

1. In what ways do postgraduate students experience their linguistic repertoires as a resource for the taught curriculum?

2. How do their experiences inform our understanding of the plurilingual social actor in Anglophone higher educational contexts?

3. How could this understanding of the plurilingual social actor be related to the teaching and learning agenda in higher education? 


\section{Linguistic repertoires and plurilingual practices}

In this section, extracts from five reflective journals are presented to provide evidence of the ways in which postgraduate students experience linguistic diversity as a resource in an Anglophone higher educational setting. The extracts were chosen to give a flavour of the complexity of the cultural and linguistic diversity of the postgraduate student population in the contemporary academy and to illustrate how an individual's relationship with English shapes the mobilisation of multilingual resources in relation to the taught curriculum.

The first extract comes from Kuzya's journal. Kuzya came from Karakalpakstan, a region of Uzbekistan. Her linguistic repertoire was composed of Karakalpak, Uzbek, Kazakh, Russian and English. She referred to Karakalpak as her 'native language' and ' $L 1$ ' and the language routinely used with family members, friends and at work. Kazakh had been learned naturally during childhood with Kazakh-speaking children in her neighbourhood. Kuzya portrayed Russian and Uzbek as mediums of instruction during schooling with Russian as the main language of instruction at university. English was learned as a 'foreign language' during schooling and used to a limited extent on her undergraduate programme in Uzbekistan. In extract 1 , Kuzya is reflecting on how she brings multilingual resources to bear on the taught curriculum for Second Language Acquisition (SLA).

\section{Extract 1: 'Three languages are mixed in my mind'}

64 The session was devoted to Instructed SLA and readings

65 were mostly about task based learning. As usual I read articles, highlighted main

66 points and took notes in English. Which is interesting I never take notes in my L1 if

67 the material is written in English. Sometimes I didn't understand some terms and

68 had to look for online materials to understand better.

69 During the session we had discussions on task based learning and raised some 70 questions on module assignment. During discussions we used English, as none of 71 us didn't share the same L1. As we have similar English language level, opinions 72 are usually expressed more simply.

73 [omitted]

74 When I got home I revised what we discussed and tried to

75 understand the main points. I use private speech when I analyse the content. Three

76 languages are mixed in my mind and I struggle to use my $L 1$ for academic thinking

77 as I cannot find proper translation of some terms. I find English or Russian easier to

78 use in such cases. Languages don't have the same structure and one word can be

79 translated in many ways according to context.

Kuzya, journal entry.

Kuzya represents herself as a diligent student who prepares herself in advance of taught sessions (lines 64-6). She starts with observations about her use of English, pointing out her use of English for note taking when reading academic texts in English (lines 65-7) and for spoken interaction when students in her group do not share 'the same L1' (line 71). This latter observation is suggestive of heterogeneous groupings in the taught sessions. 
What comes next suggests that Kuzya finds working in English only constrains her learning. She portrays herself as needing to find online materials (lines 678 ) to clarify subject matter delivered in English and having to express ideas 'simply' in classroom proceedings (line 72). It seems likely that Kuzya's limited experience of EMI frames this experience. Kuzya goes on to portray the value of multilingual resources for addressing this situation. The references to home (line 74) and 'private speech' (line 75) indicate how plurilingual practices are brought to bear on learning what she refers to as the 'main points' of the taught curriculum. Given the absence of student peers with whom she could converse in Russian, Uzbek or Karakalpak, Kuzya portrayed herself as resorting to private speech, defined by Lantolf and Thorne (2006: 75) as 'that form of externalized speech deployed by adults to regulate their own mental ... activity'. Importantly, private speech enabled Kuzya to mobilise a wider range of linguistic resources, including Russian and Karakalpak in conjunction with English. Kuzya's observation of these languages being 'mixed in [her] mind' (lines 75-6) points to her wholistic experience and resonates with Grosjean's (1989) oft-cited claim that 'the bilingual is an integrated whole which cannot be easily decomposed into two separate parts' (p. 6). Despite struggling to use her L1 in the academic domain (line 76), Kuzya still represented Karakalpak along with Russian and English as mediating her learning. Her final comment on 'proper translation' (lines 77-9) is suggestive of the issues faced in moving from self-directed plurilingual practices that, as noted earlier, allow for the 'the strategic management of imbalance' (Coste et al 2009: 20) in the repertoire, to the production of academic outputs requiring language separation based on idealised notions of 'native speaker' proficiency. For participants like Kuzya who did not represent English as their dominant language, multilingual resources played a significant role in integrating language and content and mediating knowledge comprehension.

The mediation of subject matter is developed in the second extract, which comes from Liang, a Chinese student whose linguistic repertoire comprised Mandarin Chinese and English. Liang reported using Mandarin Chinese at home, with her peers and as the medium of instruction during schooling and university. Similarly to Kuzya, Liang had learned English as a foreign language at school and prior to her MA studies had limited exposure to EMI. However, unlike Kuzya, Liang had regular access to speakers who shared her repertoire. The importance of this access comes to light in extract 2, in which Liang gives an account of how she uses her multilingual resources to comprehend taught content.

\section{Extract 2: 'I looked for the Chinese version'}

$4 \quad$ While I was reading the papers I underlined the words points and

5 sentences I found important, difficult or incomprehensible. For the unfamiliar words, I

6 looked them up in the English-Chinese dictionary and wrote down the meaning in

7 Chinese. For the unfamiliar points, I first searched the Wikipedia in English version,

8 but if I still found difficult to understand, I looked for the Chinese version. I made 
9 notes in very simple English, like 'what' 'why' or 'how' to inform myself about

10 the general information, but I used Chinese characters to summarize the key points.

11 When I came up with some ideas, I wrote it down in my notebook in Chinese. After

12 reading, I discussed with one Chinese classmate about some questions and ideas to

13 make sure that my understanding is right.

Liang, journal entry

Similarly to Kuzya, Liang starts off by presenting herself as an industrious student who meticulously attends to her studies. She starts with her reasons for highlighting particular sections of the module texts (line 5) and continues with an account of how she mobilises her multilingual resources to address the subject matter. This involved a number of plurilingual practices that made use of all four language skills, including the use of a bilingual dictionary (lines 5-6), Wikipedia pages published in Chinese and English (lines 7-8), the creation of dual language texts (lines 9-10), jottings in a Chinese notebook (lines 11-12) and spoken interaction with Chinese peers (lines 12-13).

Importantly, Liang's depiction resonates with Kuzya's account when it comes to the salience of their repertoires. Both represent multilingual resources as mediating subject matter delivered in English. Significantly, their multilingual resources are depicted as enabling them to process subject matter at a deeper level than using English in isolation. Liang also draws attention to the importance of spoken interaction in languages other than English, which in her case refers to interaction with Mandarin speakers about curriculum content. This is reminiscent of Behan et al.'s (1997) study of a French immersion programme, which demonstrated how English speakers made use of English as their dominant language to peer scaffold complex ideas in French and prepare an oral output in French.

In sum, participants with little exposure to EMI frequently portrayed multilingual resources as vital for grasping subject matter taught in English. This points to a key role for multilingual resources in self-directed and peer scaffolding activities designed to mediate comprehension of the taught curriculum in Anglophone settings.

In addition to knowledge comprehension, multilingual resources were also of significance for the development of 'functional knowledge' (Biggs \& Tang 2011). In other words, participants referred to ways in which their repertoires enabled them to put declarative knowledge to work. This is illustrated in extract 3, which comes from the journal of Felipe, a Puerto Rican student who had migrated from Spain to Puerto Rico in infancy. Felipe's linguistic repertoire encompassed bi-dialectal varieties of Spanish along with English, Portuguese and Arabic. While Felipe represented English and Spanish as languages in active use in family life, he recalled his schooling in the United States as an English-only zone in which he was actively discouraged from using Spanish. 
This portrayal resonated with the experiences of BME university students in the UK discussed elsewhere (Preece 2009, 2010, 2019), in that schooling was experienced as a place where English came to replace, rather than add to, their languages of inheritance. It seems likely that Felipe's experiences encouraged his reference to Spanish as his 'second language' (lines 13-14). Despite this, Felipe had made considerable efforts to maintain Spanish, including taking Spanish 'foreign language' classes at university, sojourning with family members in Spain and seeking out Spanish speakers in London. In extract 3, Felipe is giving an account of the high value that he places on working with culturally and linguistically diverse peers for his learning of the taught curriculum.

\section{Extract 3: 'my classmates as translators'}

5 During class ... a question arose about the grammar differences between

6 Korean, Spanish and English. After the class a group of postgraduate students including myself

$7 \quad$... began discussing the differences between the two languages. It was a

8 great opportunity to learn and share with my classmates as we began applying the different

9 concepts and theories we had learned in our Second Language Acquisition course to see if

10 they were applicable to other languages. I learned that in some languages such as Mandarin

11 there are no verb transformations. Instead, the language user relies on other words, such as an

12 adverb of time, to inflect the verb for a time change. Although I do not speak any of the other

13 languages my classmates were using as examples, and neither one of them spoke my second

14 language, Spanish, it helped us to widen our understanding of language in itself. I really am

15 enjoying taking classes with multilingual students. It enables me to see and experience the

16 world in a way that would not be available to me if I did not have my classmates as translators.

Felipe, journal entry

Felipe's reflection arises from a SLA session examining the nature of 'grammar differences' between languages that had prompted student interaction beyond the session (lines 5-7). The interaction is characterised as one of collaboration in which individual members pooled experiential knowledge of their languages (lines 5-10). Felipe goes to some length to represent this collaboration as beneficial for him with a detailed explanation of what he had gathered about Chinese grammar (lines 10-12). Felipe's commentary (lines 12-16) points to the significance of multilingual resources in such groups. As Felipe argues, the significance rested not in speaking each other's languages but in the ways that group members shared their multilingual resources to address a task. In this case, Felipe portrays the pooling of multilingual resources arising from the group's linguistic and cultural heterogeneity as enabling the application of theory to practice. Felipe's account resonates with Piccardo's (2013) discussion of pluralistic pedagogical approaches to language learning. Piccardo cites the example of Comparon nos langues (Auger 2005), in which learners of French are encouraged to compare the grammatical and lexical similarities and differences between their dominant language(s) and French. As Piccardo (2013) points out, in so doing, the students were institutionally positioned as possessors of expert knowledge for collaborative learning with peers. Importantly, the teacher's role was to scaffold metalinguistic reflection not to speak all their students' languages. Felipe's account supports this view. 
Felipe's final comment, in which he positions his classmates as 'translators' of language and culture (line 16), draws attention to the salience of multilingual resources in constructing an intercultural disposition and intercultural competence, understood in the plurilingualism literature as:

the ability to experience otherness and cultural diversity, to analyse that experience and to derive benefit from it. Once acquired, intercultural competence makes it easier to understand otherness, establish cognitive and active links between past and new experiences of otherness, mediate between members of two (or more) social groups and their cultures, and question the assumptions of one's own cultural group and environment (Beacco et al 2016: 10).

The participants made frequent reference to the salience of multilingual resources in relation to culture and the benefits of linguistic diversity for appreciating cultural diversity. The intersection of the linguistic and the cultural is highlighted in extract 4, from Fei's journal. Like Liang, Fei was a Chinese student whose linguistic repertoire encompassed Mandarin and English. Mandarin was used with family members, Chinese peers and at school, where English had been learned as a foreign language. In contrast to Liang, Fei had extensive EMI experience gained through high schooling in the United States, an international school in China and a first degree at a British university. Fei characterised these experiences as immersion in an English-speaking environment that had resulted in English becoming her dominant language in the academic domain. In extract 4 , Fei is reflecting on the value of multilingual resources for attending to different cultural perspectives.

\section{Extract 4: 'different perspectives of the story'}

60 I read some background information online in Chinese, enabling me to quickly grasp

61 the idea behind the theories. Interestingly, I found that many times Chinese version of the 62 same concepts in English actually offer a distinctive perspective. Such finding initiated my

63 thought that linguistic diversity actually creates different perspective or interpretations of the

64 same thing. Meanwhile, it becomes even more crucial that we acknowledge those different 65 perspectives of the story.

Fei, journal entry

In this extract, Fei illustrates the vitality of multilingual resources not only as an effective and efficient method of grasping content, but also as a way of attending to differing cultural perspectives of the subject matter (lines 60-2). Her use of 'many times' (line 61) suggests that the plurilingual practice of reading in Chinese and English was habitual and valued in bringing cultural differences to light. The 'we' in Fei's final remark can be understood as referring to students, or the academic community more widely, to acknowledge differing cultural perspectives in the taught curriculum (lines 64-5). Similarly to Felipe, Fei's account points to a role for multilingual resources in intercultural competence (Beacco et al 2016). It also suggests how multilingual resources 
may be mobilised to develop functional knowledge such as criticality. Despite the contested nature of this concept, Fei's account points to the idea of critical thinking as the ability to 'understand the bigger picture holistically, to see different worldviews in perspective, rather than just to critique the individual steps in a particular argument' (Mason 2008: 3). This view of critical thinking is premised on seeking out different worldviews and learning to 'contextualise our worldview within the bigger picture' (ibid.)

The role of multilingual resources in criticality is made more overtly in the final extract, taken from Aisha's journal. Aisha was a British Muslim from a BME background whose linguistic repertoire included Urdu, Hindi, Arabic and English. These languages were in use with family and community members and in religious practices. Given that Aisha had received her schooling in the UK and was as an English language teacher at a college in London, her dominant language was likely to be English in academic and professional domains. Nonetheless, Aisha was invested in her heritage languages, positioning herself as a 'native speaker' of Urdu and a graduate with a joint honours degree in Arabic and English. In extract 5, Aisha is reflecting on her knowledge of Arabic for critiquing elements of the taught curriculum that disturbed her identity (Preece 2016).

Extract 5: 'I never thought my Arabic language skills would be utilized in such a way'

18 From the readings we were given, in order to prepare for this lecture

19 there were some relatively alarming claims made ... in reference to the Prophet

20 Muhammad (peace be upon him) in terms of his teachings and thinking towards women.

21 The writer openly ridiculed his teachings, which came as a shock to me and some other

22 students in the lecture; one of the students argued that the writer's claims are completely

23 against the law and teachings of Islam which is found in the authentic resources

24 available. At that moment, I instantly recalled a Prophetic saying in Arabic "Knowledge is

25 compulsory for every Muslim, man and woman", clearly conveying the message that

26 there is no discrimination among male and female, all rights are in place for women and

27 should be given. Nevertheless, I then translated that in to English to inform the other

28 students. I thought this was quite striking, as I never thought my Arabic language skills

29 would be utilized in such ways or that I could access the language instantaneously.

Aisha, journal entry

Aisha starts by casting the module readings set by the tutor on the topic of gender equality in education as taking a problematic stance on women in Islam (lines 18-19). She signals her Muslim identity through the practice of including 'peace be upon him' when referring to the Prophet Muhammad (lines 18-20). The way Aisha characterises the scholar as 'ridiculing' the Prophet and the feelings of 'shock' this generated (lines 21-2) indicates how Aisha experienced the curriculum as at odds with her religious and gendered identity. Aisha goes 
onto portray how her knowledge of Arabic enabled her to address this disjuncture by calling to mind a saying of the Prophet. This served to produce an alternative viewpoint on gender equality in Islam for her classmates, which Aisha put forward in English during the session (lines 24-7). Her final comments on the 'striking' nature of mobilising multilingual resources suggests that this was a novel experience. It also resonates with claims made by participants in Martin's (2010) study that 'no one [takes] any notice of [the] linguistic journey' (p. 9) of BME students in UK universities (also see Preece 2009, Odeniye \& Lazar, this Issue).

So far we have seen how postgraduate students portrayed multilingual resources as salient for the taught curriculum. Under the veneer of English in which the curriculum was delivered, the participants portrayed themselves as engaged in a hive of plurilingual activity to support their learning. In the following section, I turn to a discussion of the data and a consideration of what the findings tell us about the plurilingual social actor in Anglophone higher educational contexts.

\section{Discussion and Conclusion}

This study offered a snapshot of the heterogeneous nature of linguistic diversity that characterises the student population in Anglophone higher educational settings and the value of language plurality for enriching the curriculum. Importantly, the study opened an institutional space for making linguistic diversity visible and for considering how it was a resource for the curriculum. This encouraged the participants to take a positive disposition to linguistic diversity in the institution, which was demonstrated through their willingness to scrutinise their repertoires, to reflect on ways in which they mobilised multilingual resources and to make these visible to institutional gaze. This contrasts with studies in which institutional 'language-as-problem' orientations encourage deficit narratives about linguistic diversity (Preece 2009, $2010,2019)$. This highlights the socially situated nature of plurilingual speakers in educational institutions (Marshall \& Moore 2018; Piccardo 2013) and the ways in which universities can open up or close down the position of the plurilingual social actor for students.

The study gave a nuanced view of the salience of multilingual resources and uncovered a number of plurilingual practices. An important finding was the way in which participants' relationship with English oriented them to their repertoires. Participants with little prior experience of EMI focused on multilingual resources as a way of grasping the taught curriculum. These participants referred to English as a second, foreign or additional language while another language was accorded the status of L1 and mother tongue. In many cases, this language also served as the medium of instruction in schooling and university. These participants tended to view their relationship 
with English in terms of language learning. Their accounts of plurilingual practices were reminiscent of content and language integrated learning (CLIL) in that they were hopeful that their English would improve as a result of using it for their studies (Cenoz 2015). For these participants, multilingual resources were meditational ${ }^{3}$ tools for building foundational knowledge, enabling them to take control of learning both subject matter and academic English. Extracts 1 and 2 demonstrated a variety of plurilingual practices focused on learning subject matter and illustrated how the mobilisation of multilingual resources encompassed the four language skills and the juxtaposition and separation of linguistic resources.

Key in these participants' accounts was the misalignment between teaching and learning in relation to multilingual resources. Table 2 illustrates the way in which the participants characterised the relationship in a monolingual/ plurilingual binary.

Table 2: Representations of multilingual resources in relation to the taught curriculum

\begin{tabular}{|c|c|c|}
\hline & Teaching & Learning \\
\hline Source of direction & Tutor & Self \& peers \\
\hline Medium of instruction & $\begin{array}{l}\text { One language only: } \\
\text { English }\end{array}$ & $\begin{array}{l}\text { Plurilingual: multilingual } \\
\text { resources in the } \\
\text { repertoire, making use } \\
\text { of languages 'mixed in } \\
\text { mind' }\end{array}$ \\
\hline Interactions with peers & $\begin{array}{l}\text { Inter- national group } \\
\text { work in tutor-directed } \\
\text { spaces with English as } \\
\text { the language of } \\
\text { communication; some } \\
\text { limited opportunities for } \\
\text { plurilingual interaction } \\
\text { among some group } \\
\text { members }\end{array}$ & $\begin{array}{l}\text { Intra- national group } \\
\text { work in student-led } \\
\text { spaces with those } \\
\text { sharing linguistic } \\
\text { repertoires (e.g. Chinese } \\
+ \text { English) with ample } \\
\text { opportunities for } \\
\text { plurilingual interaction }\end{array}$ \\
\hline Texts \& materials & $\begin{array}{l}\text { Reading lists \& } \\
\text { recommended texts in } \\
\text { English from recognized } \\
\text { scholarly \& reputable } \\
\text { sources }\end{array}$ & $\begin{array}{l}\text { Range of materials } \\
\text { aimed at general } \\
\text { audience (e.g. } \\
\text { Wikipedia), student } \\
\text { audience (e.g. } \\
\text { textbooks, on-line videos }\end{array}$ \\
\hline
\end{tabular}

\footnotetext{
${ }^{3}$ See North \& Piccardo (2016) for a thorough and updated account of mediation in relation to the CEFR and the development of plurilingual and pluricultural competences.
} 


\begin{tabular}{|l|l|l|}
\hline & $\begin{array}{l}\text { Session materials wholly } \\
\text { or largely in English }\end{array}$ & $\begin{array}{l}\text { etc.) in English \& other } \\
\text { languages alongside } \\
\text { tutor-directed texts } \\
\text { Language learning } \\
\text { materials (e.g. bilingual } \\
\text { dictionaries) }\end{array}$ \\
\hline Outputs & $\begin{array}{l}\text { High stakes 'products' of } \\
\text { learning in one language } \\
\text { only: English for } \\
\text { formative or summative } \\
\text { assessment by tutors }\end{array}$ & $\begin{array}{l}\text { Low stakes 'processes' } \\
\text { of learning involving } \\
\text { creation of dual } \\
\text { language and } \\
\text { multilingual texts for } \\
\text { private or peer } \\
\text { consumption. No tutor } \\
\text { input }\end{array}$ \\
\hline
\end{tabular}

Table 2 highlights how the participants characterised teaching as an immersion in English (see Marshall this Issue) in contrast to learning, which was steeped in plurilingualism. This binary needs to be treated with some caution given that the study did not involve classroom observation or the collection of data from tutors. Nonetheless, it seems likely that the participants could more readily bring multilingual resources to bear on curriculum content in spaces beyond tutor gaze. Crucially for these participants, multilingual resources generated feelings of working at a deeper level with subject matter than they could achieve using English only. All represented working in one language only as a constraint to their academic potential.

For participants who were well versed in the 'one language only' (Li \& Wu 2009) pedagogical practices of educational institutions in Anglophone settings, there was less reliance on multilingual resources for grasping subject content. These participants focused attention on how their repertoires enabled them to put subject knowledge to use in ways that resonated with the idea of 'functional knowledge' (Biggs \& Tang 2011). Extracts 3-5 suggested how multilingual resources were mobilised for the application of theory to practice, for the development of criticality and for the development of intercultural dispositions. Table 3 sets out examples of plurilingual practices linked to cultural aspects of the taught curriculum. These practices also encompassed the four language skills and were represented as mediating intercultural competence (Beacco et al 2016; North \& Piccardo 2016).

Table 3: Plurilingual practices fostering intercultural competence in the taught curriculum

- Reading in more than one language to gain alternative cultural perspectives and make these visible in the curriculum

- Collaborating with peers from different cultural, social and/ or ethnic backgrounds to pool experiential and/ or learned knowledge from different cultural contexts and/ or knowledge of other languages to 
widen understanding and broaden cultural horizons

- Using knowledge learned in languages other than English to propose alternative cultural perspectives that challenge Eurocentric notions and cultural stereotypes about the 'Other'

Plurilingual practices such as these enabled the participants to engage with the taught curriculum on their own terms. They also suggest ways in which plurilingual pedagogies and practices could be used to inform current curriculum developments in the sector that seek to address inequalities in experience and outcomes for BME students (see HEA 2018, Le Grange 2016).

What does the study tell us about the plurilingual social actor in Anglophone higher educational settings? It is fair to claim that the plurilingual social actor offered the participants a dynamic, powerful and affirmative identity position from which to speak and act within the academy. Inhabiting this identity changed the institutional script about their repertoires from one of linguistic deficits, in which they had to overcome language obstacles, to one of 'linguistic assets' (Coste et al 2009: 19), in which they could mobilise multilingual resources to support their learning. When sanctioned by the institution, the participants readily inhabited the identity of the plurilingual social actor, investing this identity with a variety of plurilingual practices that enabled them to adopt the position of an agentive being in relation to the taught curriculum in applied linguistics. This positioning offered them an alternative language identity to that of the 'native/ non-native' speaker and was available to all participants regardless of origin or dominant language(s). As such the plurilingual social actor was an egalitarian positioning, encouraging curiosity about linguistic diversity in the academic domain and open-minded dispositions towards cultural diversity among group members. To some extent, the plurilingual social actor was also an alternative to an 'elite-plebeian' bilingual identity (Jaspers 2009; Preece 2019) in that it raised the status of repertoires accorded 'plebeian' status within society and suggested how these might be brought to bear on the curriculum. This resonates with the social justice elements of the plurilingualism agenda that promote resource-based views of the linguistic repertoires of marginalised groups within the education system (Beacco et al 2016; Lüdi \& Py 2009).

The study also pointed to ways in which the plurilingual social actor is closely aligned with the higher education teaching and learning agenda. Promoting linguistic diversity in the institution enabled the participants to raise their awareness of their repertoires as resource for the taught curriculum and created a safe space to make their plurilingual practices visible. As a discursive construct, the plurilingual social actor emerged in interaction with and was shaped by pedagogical practices informed by ideas about teaching and learning in the sector. Key among these were student participation, active learning, collaborative learning, self-direction, criticality and intercultural competence (see Biggs \& Tang 2011, Ramsden 2003). This was evident in the journals in which participants oriented accounts of their multilingual resources to presenting themselves as positively disposed towards the attributes and qualities associated with pedagogical practices that were premised on these ideas. 
A key claim in the teaching and learning literature is that teaching needs to support learning and to do so those involved in teaching need to '[study] our students' learning - by listening to and learning from our students' (Ramsden 2003: 6). Applied linguists have been listening to and learning from plurilingual students for a long time. As such, we are well placed to inform the university community about what students have to say about their linguistic assets when it comes to the curriculum. We now have an emerging body of research in the sector that examines the practices of plurilingual speakers. The next step is to showcase more widely how these practices enable the teaching and learning agenda to be operationalised. In so doing, we can advance the development of plurilingual pedagogies and the idea that in educational spaces 'we are all plurilingual' (Piccardo 2013: 604), while encouraging universities to take the lead in promoting linguistic and cultural diversity as the norm in the Anglophone world. In the current political climate, this seems more vital than ever.

\section{References}

Altbach, P.G. (2016). Global Perspectives on Higher Education. Baltimore: The Johns Hopkins University Press.

Auger, N. (2005). Comparons nos langues: une de marche d'apprentissage du français auprès des enfants nouvellement arrivés [Let's compare our languages: A learning approach to French for newly arrived children]. Canope CRDP de Montpellier.

Bamberg, M.G.W. (1997). Positioning between structure and performance. Journal of Narrative and Life History, 7(1-4), 335-342.

Beacco, J.-C., Byram, M., Cavalli, M., Coste, D., Cuenat, M., Goullier, F. \& Panthier, J. (2016). Guide for the development and implementation of curricula for plurilingual and intercultural education $\left(2^{\text {nd }} \mathrm{Ed}\right.$.). Education Policy Division, Council of Europe.

Behan, L., Turnbull, M. \& Spek, J. (1997). The proficiency gap in late immersion (extended French): Language use in collaborative tasks. Le journal d'immersion, 20: 41-2.

Biggs, J. \& Tang, C. (2011). Teaching for quality learning at university, $4^{\text {th }}$ ed. Buckingham: Open University Press.

Cenoz, J. (2015). Content-based instruction and content and language integrated learning: the same or different? Language, Culture and Curriculum, 28(1), 8-24.

Coste, D., Moore, D. \& Zarate, G. ([1997] 2009). Plurilingual and pluricultural competence. Strasbourg: Council of Europe. 
Coste, D. \& Simon, D-L. (2009). The Plurilingual Social Actor. Language, Citizenship, Education, International Journal of Multilingualism, 6(2): 168-185.

Council of Europe. Council for Cultural Co-operation. Education Committee. Modern Languages Division. (2001). Common European Framework of Reference for Languages: learning, teaching, assessment. Cambridge University Press.

De Fina, A. \& Georgakopoulou, A. (2012). Analysing narrative: discourse and sociolinguistic perspectives. Cambridge: Cambridge University Press.

Grosjean, F. (1989). Neurolinguists, Beware! The bilingual is not two monolinguals in one person. Brain and Language 36, 3-15.

Higher Education Academy (2018). Inclusive curriculum. Available at https://www.heacademy.ac.uk/individuals/strategic-priorities/retention/bmeattainment-gap/inclusive-curriculum\#section-6

Hult, F.M. \& Hornberger, N.H. (2016). Re-visiting orientations to language planning: Problem, right, and resource. Bilingual Review/La Revista Bilingüe 33 (3): 30-49.

Gravelle, M. (1996). Supporting bilingual learners in schools. Stoke-on-Trent, UK: Trentham Books.

Jaspers, J. (2009). Inleiding [Introduction]. In J. Jaspers (ed) De klank van de stad: Stedelijke meer- taligheid en interculturele communicatie [The Sound of the city: Urban multilingualism and intercultural communication], pp. 7-32. Antwerp: Acco.

Lantolf, J.P. \& Thorne, S.L. (2006). Sociocultural theory and the genesis of second language development. Oxford: Oxford University Press.

Lazar, G. \& Ryder, A. (2018). Speaking the same language: Developing a language-aware feedback culture. Innovations in Education and Teaching International 55(2), 143-152.

Le Grange, L. (2016). Decolonising the university curriculum. South African Journal of Higher Education, 30: 1-12.

Li, W. (2018). Translanguaging as a Practical Theory of Language, Applied Linguistics, 39(1), 9-30.

Li, W. \& Wu, C.-J. (2009). Polite Chinese children revisited: creativity and the use of codeswitching in the Chinese complementary school classroom.

International Journal of Bilingual Education and Bilingualism 12, 193-211.

Lüdi, G. \& Py, B. (2009). To be or not to be ... a plurilingual speaker.

International Journal of Multilingualism, 6(2), 154-167. 
Marshall, S. (2010). Re-becoming ESL: multilingual university students and a deficit identity. Language and Education, 24(1), 41-56.

Marshall, S. \& Moore, D. (2013). '2B or not 2B Plurilingual?' Navigating languages literacies, and plurilingual competence in postsecondary education in Canada. TESOL Quarterly 47(3), 472-499.

Marshall, S. \& Moore, D. (2018). Plurilingualism amid the panoply of lingualisms: addressing critiques and misconceptions in education, International Journal of Multilingualism, 15(1), 19-34.

Martin, P. (2010). 'They have lost their identity but not gained a British one': non-traditional multilingual students in higher education in the United Kingdom, Language and Education, 24(1), 9-20.

Mason, M. (Ed). (2008). Critical thinking and learning. Oxford: Blackwell Publishing.

Moore, D. \& Gajo, L. (2009). Introduction-French voices on plurilingualism and pluriculturalism: theory, significance and perspectives. International Journal of Multilingualism, 6(2), 137-153.

North, B. \& Piccardo, E. (2016). Common European framework of reference for languages: learning, teaching, assessment: Developing illustrative descriptors of aspects of mediation for the CEFR. Council of Europe. https://rm.coe.int/common-european-framework-of-reference-for-languageslearning-teaching/168073ff31

Piccardo, E. (2013). Plurilingualism and curriculum design: Toward a synergic vision. TESOL Quarterly 47(3), 600-614.

Preece, S. (2009). Posh talk: language and identity in higher education. Basingstoke. Palgrave Macmillan.

Preece, S. (2010). Multilingual identities in higher education: negotiating the 'mother tongue', 'posh' and 'slang'. Language and Education, 24(1), 21-40.

Preece, S. (2011) Universities in the Anglophone centre: sites of multilingualism. In Li, W. (Ed.) Applied Linguistics Review 2. Berlin: De Gruyter Mouton, pp. 121-146.

Preece, S. (Ed.) (2016). The Routledge handbook of language and identity. London: Routledge.

Preece, S. (2019). Elite bilingual identities in higher education in the Anglophone world: the stratification of linguistic diversity and reproduction of socio-economic inequalities in the multilingual student population, Journal of Multilingual and Multicultural Development, 40(5), 404-420, DOI:

10.1080/01434632.2018.1543692 
Preece, S., Li, W., A. Creese, A. Blackledge, J. McPake, \& Block, D. (2016). The Multilingual University: The Impact of Linguistic Diversity on Higher Education on Higher Education in English-dominant and English Medium Instructional Contexts. ESRC Seminar Series.

https://multilingualuniversity.wordpress.com.

Preece, S., Griffin, A., Hao, Y., \& Utemuratova, G. (2018). Examining linguistic diversity as a resource for higher education in the Anglophone world. In V. Tong, A. Standen, M. Sotiriou (Eds.), Shaping higher education with students: Ways to connect teaching and research. London: UCL Press, pp.

Ramsden, P. (2003). Learning to teach in higher education, $2^{\text {nd }}$ ed. London: Routledge Falmer.

Ruiz, R. (1984). Orientations in Language Planning. Journal of the National Association for Bilingual Education, 8 (2), 12-34.

Simpson, J. \& Cooke, M. (2010). Movement and loss: progression in tertiary education for migrant students. Language and Education, 24(1), 57-74.

Study London (ND). UK Student Visa (Tier 4) Requirements.

http://www.studylondon.ac.uk/application-advice/uk-student-visa-information.

Tong, V.C.H., Standen, A. \& Storiou, M. (Eds.) (2018). Shaping higher education with students: ways to connect research and teaching. London: UCL Press.

Touraine, A. (2000). A method of studying social actors. Journal of WorldSystems Research VI(3), 900-918.

UNESCO Institute for Statistics (2015). Glossary. http://glossary.uis.unesco.org/glossary/en/home

Vertovec, S. (2007). Super-diversity and its implications, Ethnic and Racial Studies, 30 (6), 1024-1054, DOI: 10.1080/01419870701599465 